\section{THE INAUGURAL ADDRESS}

$$
\text { ON }
$$

\section{THE ART OF WRITING IN RELATION T0 MEDICAL AND SCIENTIFIC WORK.}

Delivered before the Society of Medical Phonographers.

BY W. R. GOWERS, M.D., F.R.S.,

President of the Society.

Gentlemen,--I have the pleasure and the privilege of welcoming sou to the first meeting of a Society which is the first of its kind. No systematic effort has before been made to promote the work of a profession by the special means we employ. These means are the immediate reason for our existence, but they are means alone. I would emphasise at the outset the fact that the object of our Society is to promote medical knowledge, to facilitate its acquisition, and especially to augment its application. Beyond this, as beyond all the work of our profession, is the ultimate object-the welfare of others. The fact that the effort to achieve these results can be aided by a special means-the use of shorthand-is the immediate reason for our existence, but it is not our ultimate object.

Why, however, does this reason exist? Why is there a need for our society, at least sufficient to have induced its formation and to have produced a bright promise of success ?1 Because a hindrance exists to the best and highest work of our profession, a hindrance that is not essential in the nature of things. It is one of the many elements of our life and work that have come to us from the past. The past holds the present firmly in its grasp. With the vast change of modern progress, there is persistence of much that has changed little or not at all. To such persistence we owe indeed the stability of the present; this depends on the permanence of that which is beneath us; that which, upon the surface, remains unaltered amid the changing elements of progress, often involves a hindrance to action and to work.

Why should a surface hindrance persist and thus retard? That is, indeed, our own question. The answer, however, is instructive and interesting. However firm is the grasp of the past on the present, it is seldom felt. Wordsworth has told us in a familiar line that

$$
\begin{aligned}
& \text { Custom lies upon us with a weight } \\
& \text { Heavy as frost. }
\end{aligned}
$$

But the weight of custom, like that of the atmosphere in and under which we live, is all unfelt. "Use and wont,"

$$
\text { Old sisters of a bygone day, }
$$

Gray nurses, loving nothing new,

do not allow us to see clearly that which they have charge of. Habit, personal familiarity from early life, perhaps augmented by influences transmitted through many generations, blinds us to the imperfection of that which is familiar It likewise distorts the image of that which is novel, and makes it impossible for definite superiority to be duly perceived.

Caxton gave us mechanical writing, and stopped all change. Through the centuries since, the sounds of speech have been presented to the eye by symbols that have undergone no material alteration. They are now, indeed, little less clamsy than when the Phœnicians and Egyptians first gave alphabetical writing to mankind.

Consider our present system of writing as a new invention. Conceive the reception that would be given to it as a nineteenth-century device for presenting to the eye the sounds of speech, for symbolising the movements of articulation by movements of the hand. Its defect is only in slight degree a matter of spelling. The reformation of our present "orthography" (as it is termed by an inverted metaphor) would leave untouched the cumbersome symbolism of current writing. It is not only cumbersome, but laborious. About five different movements of the hand are required to represent each simple movement of speech, and often this number

1 The Society was started in December, 1894, with sixty members, and has now (September, 1895) 175. Information regarding it and the short hand medical periodical and other publications that are issued can be obtained from the Honorary Secretary, Dr. Neil, Warneford Asylum Oxford. is doubled or trebled. Writing can only be easy and simple when the movements of the hand that symbolise each movement of speech and its resulting sound are the fewest compatible with secure and ready perception by the eye. Such simplicity is the basis of phonetic shorthand. It is the facility thus obtained that we desire to extend in the use of the art of writing essential for the work of our profession. Our object is to promote that work by the use of a method of writing that needs at the most only one-third of the time and one-third of the trouble of longhand, and yet has an average legibility more prompt and more secure.

The need for writing in medical work will be self-evident to most, but, perhaps, not to all. Yet its grounds are sufficiently conspicuous. The knowledge has been obtained by observation, and is increased through life by personal observation, and by reasoning based thereon. But in every science that rests on observation, the need for written record is absolute. No memory. whatever its capacity, can be trusted. Immediate record alone can make observation effective. That which is secured by the use of shorthand, even at a low speed, is this : in a given time there can be twice the amount of record that is possible with longhand, and yet twice the time in which to observe. For the greater amount of record observation must be more minute, more precise. Description at once reveals unsuspected uncertainties, and the greater the amount of record the more accurate is the observation, the more valuable is the result. The effect of the use of shorthand is, and must be, on the quality of scientific work so far as observation is concerned. Nor is it alone a matter of quality. Many of the facts observed are changing, passing. In these the effect of the use of shorthand is not merely qualitative; facts can be described which longhand could not possibly record. It must be remembered that shorthand enables, when necessary, not twice, but three and four times the amount of record, and thus transient phenomena can be adequately described which would elude entirely the slow pursuit of longhand, however abbreviated. The difference is thus absolute ; observations can be secured that would otherwise be lost. These facts are true of our work as a branch of natural science. ${ }^{2}$ I emphasise them because the statements are true of every science which rests on observation, and in all natural sciences the art we advocate would of necessity increase the capacity of every worker, and augment the value of his work. We venture to hope, indeed, that the influence of our Society may ultimately extend the use of shorthand in many other branches of intellectual work and especially in natural science.

But no effect on the quality of work is limited thereto; the worker is influenced as well as the work. If a man habitually observes more fully, more precisely, and more carefully, he must become a better observer, able to perceive more accurately, more minutely, more adequately, and to attain precision more readily. This influence, moreover, whatever its degree. must be progressive. We might take as our motto the words "Writing maketh an exact man."

The use of shorthand in science does not stop at the record of observation. It is equally available, with the same saving of time and labour, in the processes of comparison of observations, of epitomising the facts observed by others, and in all the preliminary work of composition. Indeed, I have frequently written the final copy in shorthand ; typewriters transcribe it with accuracy, and it is only a question of demand for shorthand MS. to be accurately put up directly in ordinary type.

These remarks have special reference to the work by which medical science is increased and improved. It may be thought that they have little application to the work of the practitioner. Such an idea is a mistake, and, like most mistakes, is instructive by its error. The capacity of shorthand to promote the work of our profession attains its maximum in the aid it can give to the practitioner. Further, the aid it can give the practitioner does not essentially differ from that which it affords to higher scientific work, and the fact is worth noting.

For what is the work of the practitioner of medicine? Of

${ }^{3}$ This point was well expressed in a letter read to the meeting from the Bishop of Hereford ( $\mathrm{Dr}$. Percival), formerly head master of Clifton and of Rugby: " Shorthand puts a new instrument into the hand of the observer. an instrument which must be specially valuabl 
all those who toil in the busy hives or barren deserts of this earth of ours, he stands in one respect alone. His daily work is to apply science to human need. He avails himself of the knowledge that we have of the processes of Nature without and within the human frame, to strive to avert or arrest disaster to life. He starts equipped with a certain amount of knowledge-as much as he can receive from those who teach him. But he learns more from each day's work. Facts come before him every hour, facts sometimes new, and often new to him. His ability depends on his use of them, on the exactness of his observations, on his adequate retention of their lessons. No practitioner can do his daily work with any competence without constantly observing for himself, constantly reasoning from his observations. The work of the medical practitioner, high or low, is personal science, as that of no other worker is.

Cavil as we may at the word " gcience" no distinction can be drawn between the work of the medical practitioner and that of the highest scientist, save in degree and in the fact that the knowledge is gained chiefly for application. The latter is, indeed, rather a spur than a hindrance. It involves special risks of error, but these are not inevitable. The point to (which I would lead you, however, is that for each one of us in our daily work precise record is as necessary as for the advanced investigator. Without the use of writing the facts that pass before him will leave only a transient furrow on the sands of unaided memory, vanishing for the most part when new facts disturb the surface, obliterated by the first of the strong gusts that come and change and go, or at most leaving but a slight modification in mental tendency. Without record there can be no precision; without precision there can be no certainty either of inference or of action. The vague effect of unrecorded-and therefore unconsidered"experience" is too often a warping of judgment by the influence of some striking but exceptional fact, conspicuous in vague outline in the memory, while the conditions essential to its interpretation are forgotten. Only habitual, immediate record can preserve from these dangers the " personal science" on which depends the work of the practitioner and the welfare of his patients. For this result the record of that which is observed must of course be utilised and so arranged that its value shall not be lost. Yet the mere process of record gives, as we have seen, precision to observation and secures retention, not otherwise to be obtained.

For all this personal use of writing, phonetic shorthand is available with unmixed advantage. Properly written at three times the speed of swift longhand, it can be read as fast as the lips can move, even if written by another person. To teach the mode of employing it to most advantage, and the method of adapting the record to subsequent use, are among the objects of our society, and information on these subjects has already been published by it. I would add, moreover, that the persistent and increasing help to the practitioner's work, obtained through the facility of record that shorthand affords, is a matter of personal experience to which many members of our society can bear the strongest testimony. We have among our members those who have used it with great advantage during forty years, although we cannot produce a rival to Dr. Hall Gladstone, whose use of it in science dates from 1846.

I have said nothing yet of the value of shorthand to the gtudent in gaining the knowledge which the collective wisdom of the profession decrees that he shall obtain by the ear. Shorthand enables a student to make a perfect epitome of his lectures, more useful than any textbook, and yet give more attention to the subject than if he took no notes. To attempt to secure a full report of the superfluous verbiage with which almost every lecturer conveys knowledge is a profound mistake. It is an instance of the misuse of the facility in writing which shorthand affords. There is no useful thing, however precious, which may not be misused.

The student's training comprises also the acquisition of knowledge by personal observation - a method of learning which has to continue through life. On his skill in this much of his future ab lity depends. Here shorthand is of peculiar value. It renders the help already described, and. in addition to record of facts, he is able to secure the com ments on them given by his teachers, which it is scarcely possible to secure at the bedside by longhand. Properly used, the influence of shorthand on the student's academical career is certain and not small, but far more important is that which it exerts on his futare work. He starts cn higher level, with the means of a more rapid rise to thorough practical power.

During the two months long vacation a student can easily acquire a knowledge of shorthand sufficient to make it serviceable and to insure its increase by use. But the object to be desired is that it should be acquired before the nedica education is commenced. Many students are now using it to the utmost advantage who learnt it before the commencement of their medical studies. No greater service can be done to any intending student than to secure this acquisition. It is now taught in a large number of public schools, but unfortunately when a knowledge of it is gained it is allowed to drop. Its use is not inculcated, and the lad has forgotten so much of it when he begins his medical carepr that, without special motive, he does not revive it. The remedy is simple. Shorthand should be an extra. markbearing subject in the preliminary examination for the profession. It would displace nothing. Competence in all other subjects would be untouched. The effect on a larg number of future members of the profession, on all their work -practical and scientific-would be vast. Some years ago this subject was brought in vain before the General Medical Council, in whose hands the decision lies. But our thanks are due to Sir Dyce Duckworth and Mr. Wheelhouse for their initiation of an effort which must sooner or later be successful.

Although the use of shorthand through life can best begin with the student's work, it has been repeatedly learnt some years after practice was commenced, and its service has been quickly and effectively obtained.

It is a prevalent idea that shorthand can be written but cannot be read. But no writer who has a moderately good knowledge of phonography will fail to confirm my statement that, written at the rate I have mentioned, at three times the average speed of longhand it can be read with far greater security than the longhand, whether the reading is by the writer or by another person. The popular error that it is illegible is due to the immense number of shorthand writers who learn only to write and to immediately transcribe and who have taken no pains to secure the ability to read. $\mathrm{Be}-$ cause reading is not a spontaneous result of writing it is assumed to be impossible. The ability to read shorthand can indeed be acquired perfectly without any ability to write it, and is sometimes acquired.

With respect to the time needed for the acquisition of shorthand, this can be much reduced if the learner chooses to give more time each day and does avail himself of the help of lessons. The art of teaching shorthand has been of late years developed to a remarkable degree. An interesting $\mathrm{PX}$ periment has been lately carried ont on some members of our profession by Mr. Hayns, of the Westminster School of Shorthand. which shows that if a man chooses to give to the study two hours a day, with a lesson each day, in a fortnight he will be able to write it at the same speed of longhand, and at the end of a month will have secured its practical use.

Although the swiftest writing ever achieved has been by this system, for our purpose moderate speed and perfect ease are all we need. With three times the speed of longhand, more than three times the ease of writing, and a definitely greater legibility, we may be reasonably content, and it is this we desire to promote in our profession.

If such a combination of speed, ease, and security is at the disposal of anyone who chooses, why do not more avail themselves of the help? Because, like so many other things, it needs a present sacrifice for future good. It needs the power to make that which may be, as potent a motive as that which is. To each man comes, by choice or by necessity, the daily task. The present is actual, the futare is only possible, or at most probable. That which depends on the imagination, excited by the assurance of others, is seldom an influence comparable to those motives which are at hand. and directly conspicuous to consciousness. Hence it is that so few acquire our art, even if they give an abstract assent to the assertion that they and the patients whom they help will be the better for it. They may believe the assurance that the daily hour devoted to the study for a few weeks will be regained within 
a year, but there is the present work, ever pressing, and this claims the time and gains it. We talk of the power of the imagination, but bring it in relation to action, and it is seen to be feeble compared with the power of that which is a present reality. What influence on the mind is excited by narrated suffering compared with that produced by witnessed agony? The one is as real as the other, but the intense distress of indignation excited by that which is seen is never equalled by that which is imagined. The difference in motive power is the great hindrance to the acquisition of shorthand as an aid to work that can be done without it, if less adequately. The time that is required to gain the greater power has to be taken from present work; it has to be taken on the assurance of others, and the effect of the assurance fades under the pressure of the present. It may be influential for a week or two, but then the path begins to seem long. The daily time is shortened, then a day passes without study, and soon there comes the realisation of the statement of Whately, that " that which ceases to be habitual, soon becomes habitual in its ceasing." The result is that the attempt is given up. or the knowledge that is acquired is so imperfect as to induce an impression of its capacity, inadequate and erroneous, or a quite mistaken idea of personal inability.

Yet it should not be so. The facts I have dwelt on can be testified by scores of members of our Society, and those who will trust the testimony will not long need such assurance. They will soon have personal experience that will make them altogether independent of the testimony of others.

But it will be asked, Are there no drawbacks to the use of shorthand? One alleged drawback is this: it has been said that the constant practice of making notes. weakens the memory; lessens the power of retaining facts without notes.

Without doubt the more the unaided memory is depended on. and cultivated, the greater is its retentive power. But I believe that, as a drawback to the use of shorthand, this impression is an illusion. It is due to the comparison between the extent and precision of the facts secured by record with the small extent and uncertain character of those which are, and alone can be, retained by the memory. The result is a comparison in which the memory seems far more inadequate than it is. The inadequacy of memory is realised as it cannot be by those who trust to it alone, and is ascribed to the use of shorthand. But, if shorthand is properly used, it will involve the retention of a greater amount of knowledge by the memory. If the recorder is not content with a mere mechanical record, but notes mentally while he records; and especially if he, as he should do at the end of his day's work, reviews the record and considers the lessons of the facts, it will be found that far more is remembered, and that this is remembered better than would otherwise be possible. But even if the opinion were true that the practice of noting all important facts has an influence on the retentive power of the memory - and I am not at all disposed to grant the truth of the opinion as regards the proper use of shorthand-there can be no question of advantage of the two habits thus placed in comparison. To permit this to deter from the acquisition and use of shorthand is, in a degree of more than usual accuracy, to be "penny wise and pound foolish."

For all this, shorthand must be properly known. The great pitfall for medical phonographers is the fact that it can be used for personal purposes when inadequately known, and that the user does not discern how great is the difference in degree, even of personal service, which is entailed by imperfect knowledge. This is, of course, only the assertion that no machine can be properly used until it is thoroughly mastered. Unless some initial trouble is given to bring the knowledge of shorthand to definite adequacy, its full value will not be obtained. Moreover, in accordance with a general law, the absence of that which has not been gained will not be realised. The loss of that which has been is keenly felt the loss of that which might be, however great the real misfortune it entails, is unperceived.

If we can accomplish these objects, in whatever degree we are successful in our efforts we shall in that degree do more good than we can realise, more than we can see or learn. But this is not all. No good can be done, or, for the matter of that, no evil, which has not its own indirect results of the same character. Such an influence as I have spoken of gives increased knowledge, which, as I have said, is above all the "knowledge that is power." No man can gain more knowledge without obtaining at the same time more power of acquiring other knowledge. The increased opportunity to learn, which the use of shorthand gives us, causes of necessity an increased ability to learn, and the process of increase in ability goes on and on.

Lastly, whatever our Society can achieve is, like all the work of the profession to which we have the honour to belong, for the good of others. Our immediate object, indeed, may be to our own existence and that of those dependent on us. We can claim no immunity from that mysterious blessing which, in the guise of a curse, accompanied our far-off ancestors in one of the changes they passed through, when labour became the price of life. But the work which we do, by which we live, is that by which as far as may be others live. Whatever good we can achieve, who are here banded together for a common object, is for the benefit of those who in their need depend on our profession. Save for the rare occasions when the use of shorthand can secure some precious words of wisdom that would otherwise be lost, its service to men is greatest when it facilitates, increases, makes more effectual the work that is for others. What the work of our profession is I need not tell you. But this I may tell you, that whatever is the degree of the special help we give to the work of our profession, that help will not be transient, will not be narrow, will not be doubtful. It will endure as long as the science and the art of medicine; it will be wide as the disease we combat; it will be certain as the death we endeavour to postpone.

\section{OPENING OF THE MEDICAL SCHOOLS :}

\section{INTRODUCTORY ADDRESSES,}

\section{ST. GEORGE'S HOSPITAL.}

\section{THE HISTORY OF ST. GEORGE'S HOSPITAL, WITH} SOME REMARKS ON IDIOSYNCRASIES.

\author{
By G. D. Pollock, F.R.C.S. \\ Consulting Surgeon to the Hospital.
}

AfTer a few introductory observations Mr. Pollock said: It may intert st you to learn something of the early life of our school and of the arrangements formerly provided for the teaching of anatomy and other subjects. I need not dwell long on the past history of our hospital. Those interested in the question may refer to an account drawn up in 1866 by Dr. Page, then one of our physicians. The hospital was originally Lanesborough House, the private residence of the nobleman who held that title. It was purchased by the governors of the hospital, and opened for the reception of patients in 1733. But it was found ill adapted for the wants of such an institution; patients suffering from disease and accidents increased so greatly in number that the accommodation was soon found to be insufficient, and it was at last decided by the governors to rebuild the hospital, and this was effected in 1833.34.

But, at that more recent period, the requirements of a thoroughly efficient and convenient hospital, perfect in all sanitary arrangements, were but little understood. The defects of the building, as originally constructed, have been a source of constant and yearly expense in the endeavours to meet the demands of sanitary efticiency and other necessary arrangements. I need not enter into details, but there are still some marked drawbacks, which I hope hereafter may be remedied by the rebuilding and considerable extension of the hospital in the direction of Hyde Park Place. I am sanguine enough to hope and believe that sooner or later -but the sooner the better-the governors will see the importance, if not the necessity, of carrying out such a scheme, and I am glad of the opportunity of thus publicly ventilating the question.

In the rebuilding of the present hospital but little provision was made for the conduct of a medical school. A small lecture room adjoined the original museum. There was not any accommodation for teaching anatomy. The 